Mini Review

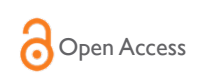

CrossMark

\title{
Celebrities, drugs, mortality and survival
}

\begin{abstract}
Celebrity actors and singers who remain popular in the public's eye are typically doing well. For this lucky group, the fame and fortune has lasted decades. For others who are less fortunate, one reads or otherwise learn that the 'fallen' celebrity has been ill following a period of drug abuse. Unfortunately, this seems to be a typical scenario of celebrity performing artists, who have seen the peak of their careers. The ones who seem to persevere to do well, and those who continue to receive public approval for their public actions are the ones who are spiritual/religious and are doing good for a worthy cause. Good living examples are provided.
\end{abstract}

Volume 7 Issue 2 - 2017

\section{Kaufui VWong, Miami U}

Department of Engineering, University of Miami, USA

Correspondence: Kaufui VWong, Department of Engineering, Mechanical and Aerospace Engineering, University of Miami, Florida, USA, Email Kwong@miami.edu

Received: December 30, 2016 | Published: February 08, 2017

Keywords: singers, actors, mental health, illegal drugs, fatality

\section{Introduction}

It was difficult to read, during Christmas week 2016, that Carrie Fisher, who played the iconic role of 'Princess Leia' in the movie, Star Wars, has passed away. She was the popular daughter of American movie stars Eddie Fisher and Debbie Reynolds, and only 60years old. She was also an accomplished author of many books. In the week before her demise, she had suffered a heart-attack on a plane. Like many of the American actors and singers of the 'Flower Children' generation, she battered with drug addiction.

Other well-known singers who took drugs were the brothers who made up the Bee Gees, and so did the African American singer, formerly known as 'Prince'. So too did Michael Jackson, the superstar singer. Other performing artists include Jim Morrison, Jimi Hendrix, Janis Joplin and Judy Garland; they all died after a period of drug abuse.

Performing artists in the United States of America (USA) tend to take drugs to reach outside their normal selves, especially when they have reached a plateau in their careers. In general, they are probably looking for one more angle/hit to make themselves 'shine' again. Those who do go the route of drugs, are normally not spiritual or religious; furthermore, because of their previous successes, they have the means to buy the illegal drugs. It is a great thing that Singapore and Malaysia have very heavy penalties on illegal drug use. This is also true too in the first, second, and fourth most populous countries in the world, viz. China, India and Indonesia.

When the author searched online in the Internet, 'Which singers died from drugs?', about ten million and a half results were obtained in 0.69 seconds, a record search result for the author. Granted that many of these search results would be repetitions about the same artist, but it speaks to the extent of the cultural problem that has produced a concomitant mental health problem which ended in fatality in many cases.

\section{Mini literature survey}

Reference $^{1}$ is about celebrity culture. Celebrity culture grew into a portion of social life, particularly in the West. Cashmore's tome ${ }^{1}$ goes into the various aspects of this celebrity culture. He goes into 'fabricating fame', 'worshipping from afar' by the masses and other interesting issues related to this culture.

Reference $^{2}$ is a book about the culture of celebrities, and how it opens up a whole branch of the 'American Dream' of material success.
Very desirable epitaphs have been attached to celebrities like 'star', 'stardom' and great 'social mobility'. It is not difficult to imagine how the young can be easily influenced to try to follow that path to fame and fortune.

Reference $^{3}$ is another book on drugs and popular culture. That celebrities are more exposed to the abuse of illegal drugs can be deduced from the culture that exists amongst them, and that they have the financial means to acquire them.

In reference Shaw et al., ${ }^{4}$ studied celebrity drug abusers. They ask the interesting question, 'Does media coverage of celebrity drug use pose a risk to young people?'

In reference, ${ }^{5}$ Culpepper discusses positive psychology for treatment. Culpepper writes about a case study of an alcoholic. There is close relationship between alcohol addiction and illegal drug addiction. The branch of positive psychology appeals to the inner goodness of the drug abuser to initiate and continue the healing process to complete recovery. It is essential for complete recovery that the abuser turn away completely from the addictive drugs. It is crucial for survival.

\section{Discussion and Conclusion}

There is the first person view of the person who uses illegal drugs, and there is the third person view of society-at-large, i.e., the psychologist/psychiatrist and the community. With these two views at least, scientific methods have been used, and reasonable successes have been achieved. If, however, the third person view is no longer enforced, as it would seem in the celebrity culture in the West, it is unlikely that the normal healing process used by non-celebrities would succeed.

In other words, it is being presented here that the community which grant celebrity status to a person for his/her talent and popularity, should also be the community who censure the use of illegal drugs or else the celebrity will not change.

The misconduct anxiety within an individual can be deduced to be not strong enough to stop/prevent the consumption of illegal drugs by the psychologically sick celebrity. It remains for external factors to influence this reprehensible habit. Besides the reversal of adulation discussed above, the impossible costs of illegal drugs could be another. If a celebrity performer loses the public's adulation and the related enormous pay-checks, then the celebrity will not be able to afford the costs of the illegal drugs. 
Another factor which might contribute to a reversal of national attitudes is that much of the world outside the West, have censured the use of illegal drugs. Punishments are heavy, even to the extent of death to illegal drug users e.g. Indonesia, Malaysia, Singapore. Other countries in the Middle East and elsewhere use this permissiveness of the West to detract the West from leadership in the World. It is a worthwhile consideration that for the West to maintain a sustainable leadership in the World, the West should change this aspect of celebrity culture of taking recreational illegal drugs.

An uplifting example is Willie Nelson, the country-and-western singer who used to take drugs. ${ }^{6}$ In,${ }^{6}$ it was claimed that Willie Nelson smoke marijuana on the roof of the White House in the USA. He has now focused his energies and resources to a scientific/engineering pursuit, 'biodiesel'. In this pursuit, Willie Nelson is doing good for the environment as well as for the nation, by providing jobs, etc. Celebrities in trouble could probably look to him as a good example, as a recovered drug abuser who has become spiritual again (not for any particular religion necessarily) through his devotion to science.

Performing artists, especially singers and singer-songwriters, are influencers of the young. It is right to proclaim that influencers while communicating to the young, should not be under the adverse influence of drugs. To this end, we and celebrities can look towards good examples like Bono, born Paul David Hewson, the lead vocalist of U2, the Irish pop band, and Kartika Jahja, the Indonesian singer-songwriter. Bono is a venture capitalist, businessman, and philanthropist ${ }^{7}$ with no public drug-abuse history. Kartika Jahja, ${ }^{8}$ also known as 'Tika', is an activist for women's rights and gender issues in the Muslim country of Indonesia. It is unlikely she ever took drugs or traffic them, seeing how it brings the death sentence in Indonesia when one is caught.

\section{Acknowledgments}

None.

\section{Conflicts of interest}

Author declares there are no conflicts of interest.

\section{Funding}

None.

\section{References}

1. Cashmore E. Celebrity culture. Routledge, UK. 2006.

2. Sternheimer K. Celebrity culture and the American dream. Stardom and social mobility. Routledge, UK. 2011.

3. Manning P. Drugs and popular culture. Routledge, UK. 2013. p. 304.

4. Shaw RL, Whitehead C, Giles DC. Crack down on the celebrity junkies': does media coverage of celebrity drug use pose a risk to young people? Health, risk \& society. 2010;12(6):575-589.

5. Culpepper LD. Positive psychology and spirituality. J Psychol Clin Psychiatry. 2016;6(7):00407.

6. Patoski JN. Willie Nelson: An Epic Life. Hachette Digital, NY, USA. 2008.

7. https://en.wikipedia.org/wiki/Bono

8. https://en.wikipedia.org/wiki/Kartika_Jahja 